Revista de
Economild
Contemporâned

\title{
CENTRO E PERIFERIA NAS CADEIAS GLOBAIS DE VALOR: UMA INTERPRETAÇÃO A PARTIR DOS PIONEIROS DO DESENVOLVIMENTO
}

\author{
Fernanda Graziella Cardoso ${ }^{a}$ \\ Cristina Fróes de Borja Reis ${ }^{b}$ \\ aProfessora Adjunta do Bacharelado em Ciências Econômicas da \\ Universidade Federal do ABC (CECS/UFABC).

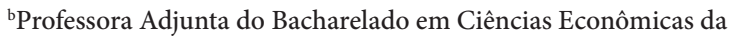 \\ Universidade Federal do ABC (CECS/UFABC) e pesquisadora visitante do programa \\ IPODI Marie Curie na Technische Universität Berlin.
}

Artigo recebido em 14/10/2017 e aceito para publicação em 21/09/2018.

RESUMO: O artigo objetiva reconciliar teoricamente a realidade atual das cadeias globais de valor no início do século XXI às lições dos pioneiros do Desenvolvimento sobre as possibilidades de desenvolvimento econômico via comércio internacional. Para tanto, realiza-se uma discussão teórica destacando algumas das principais ideias daqueles autores, visando,em seguida, revisitar o conceito de centro-periferia no contexto da divisão do trabalho atual a partir da análise dos dados do FMI, Banco Mundial, e TIVA/OECD. Conclui-se que a divisão centro/periferia permanece, porém remodelada: ainda há uma expressiva diferença de renda entre os países ricos e os demais, que coincide com as discrepâncias na complexidade das exportações, nas estruturas do emprego e, finalmente, mas não menos importante, na produtividade agrícola.

PALAVRAS-CHAVE: desenvolvimento econômico; cadeias globais de valor; estado; inserção externa.

CLASSIFICAÇÃO JEL: B31; F63; O10. 


\title{
CENTRE AND PERIPHERY IN GLOBAL VALUE CHAINS: AN INTERPRETATION BASED ON THE PIONEERS OF DEVELOPMENT
}

\begin{abstract}
The article aims to theoretically reconcile the reality of global value chains in the 21st century to the lessons of the pioneers of the Development Economics about the possibilities for economic development through international trade. Therefore, the theoretical discussion highlights some of the main ideas of those authors, and then the concept of center-periphery is reviewed in the context of the current labor division by the analysis of data from IMF, World Bank, TIVA/OCDE. The conclusion is that the division center/periphery remains, but reframed: there is still a significant difference in income between the rich countries and the others, which coincides with the discrepancies in the complexity of exports, in the employment structures and, last but not least, in the agricultural productivity.
\end{abstract}

KEYWORDS: economic development; global value chains; state; foreign insertion. 


\section{INTRODUÇÃO}

No contexto do pós Segunda Guerra Mundial, em que se define a abordagem teórica da Economia do Desenvolvimento ${ }^{1}$, uma série de autores pioneiros (Rosenstein-Rodan, Nurkse, Hirschman, Kalecki e Prebisch, dentre outros) retoma o argumento de “indústria nascente" de List (1856), colocando a industrialização como o caminho para a superação do subdesenvolvimento. Naquele momento, estava clara a impossibilidade de se alcançar o desenvolvimento pautando-se na clássica divisão internacional do trabalho, que Prebisch (1949) traduzirá no conceito de centro-periferia (resgatado dos teóricos do imperialismo) e na tese de tendência de longo prazo à deterioração dos termos de troca dos bens primários relativamente aos bens manufaturados. Para a consecução da industrialização, fazia-se necessária uma ampla e profunda atuação estatal, seja como planejador, seja como investidor. Só assim, a estratégia de investimento em bloco do Big Push preconizado por Rosenstein-Rodan (1943), ou o aproveitamento das potencialidades dos encadeamentos para frente e para trás destacados por Hirschman (1958), seriam capazes de superar o círculo vicioso da pobreza de Nurkse (1953) - conceitos fundamentais que serão debatidos ao longo deste artigo.

Porém, será que, depois de mais de meio século desde que as ideias desenvolvimentistas abordadas foram gestadas, seria ainda a industrialização o caminho mais promissor para a tentativa de promoção do desenvolvimento econômico? Se sim, qual seria a forma de industrialização? Se não, qual seria o caminho mais promissor? E a clássica configuração centro-periferia continuaria válida? Essas questões são objeto de reflexão deste artigo.

Sem embargo, com o avanço da industrialização, o que se observou foi o recrudescimento da heterogeneidade estrutural, na medida em que a indústria não poderia ensejar uma dinâmica que absorvesse o fator mais abundante: o trabalho. Como resultado, não se enfrentou a outra condição definidora e aprisionadora do subdesenvolvimento, os elevados níveis de desigualdade, seja entre regiões, seja entre classes sociais. Observando a trajetória do Brasil no pós-guerra, Furtado (1975, p. 86) resume: “[a] sociedade se moderniza antes de que a economia se desenvolva”. Desse modo, no chamado período desenvolvimentista, apesar do avanço na matriz industrial e da suposta modernização, especialmente pela emulação dos padrões de consumo dos países desenvolvidos por uma diminuta elite econômica, as desigualdades se aprofundaram. E esse será o resultado também observado em boa parte da periferia, especialmente a latino-americana, que sofrerá ainda um novo golpe: a crise da dívida da década de 1980.

\footnotetext{
1 Neste artigo, utiliza-se o termo "Economia do Desenvolvimento" para o pensamento dos pioneiros a partir dos anos 1940 do século XX, em conformidade com Arndt (1987, p. 47-48).
} 
Por outro lado, desde os anos 1980, os fluxos internacionais de capitais, bens e serviços trouxeram transformações profundas na divisão internacional do trabalho, ou nas chamadas cadeias globais de valor $(\mathrm{CGV})^{2}$. Lideradas por empresas multinacionais, a produção fragmenta-se geograficamente no mundo não somente por meio das exportações, dos licenciamentos ou dos investimentos diretos (DUNNING, 2001), mas também sob formas mais flexíveis de contratos, que regem movimentos de terceirização, modularização, realocação e diferentes tipos de servitização. De acordo com relatórios da UNCTAD (2013) e da OMC/OCDE (2013), na atualidade as CGV respondem por mais de $80 \%$ das exportações mundiais. Os fluxos de investimento estrangeiro direto estão altamente relacionados com as decisões sobre a distribuição das CGV, impactando, significativamente, as regiões e ocrescimento dos países. Em especial, o período de 1990 a 2010 foi marcado pelo extraordinário crescimento de países periféricos, de modo que alguns deles promoveram a industrialização - como China; enquanto outros se aproveitaram da elevação sustentada dos preços das commodities, apostando no modelo primário exportador, como boa parte dos países africanos e latino-americanos.

A partir do entendimento desse novo contexto, o artigo objetiva identificar algumas das lições sobre as possibilidades de desenvolvimento econômico associadas ao comércio internacional sugeridas pela Economia do Desenvolvimento. Tal intento pretende auxiliar na interpretação das consequências da inserção dos países periféricos nas CGV, culminando, potencialmente, com uma concepção renovada do que é centro e periferia no século XXI.

$\mathrm{O}$ artigo se divide em duas seções, além desta introdução e das conclusões. A seção 1 perpassa a história das ideias da Economia do Desenvolvimento, recorrendo a algumas das principais contribuições de autores pioneiros selecionados - destacadamente, Prebisch. Na seção 2 retoma-se o conceito centro-periferia, reconciliando-o com o novo contexto de cadeias globais de valor, a partir de variáveis ilustradas conforme recursos mais modernos de visualização espacial disponíveis nos principais bancos eletrônicos de dados macroeconômicos. As conclusões retomam os achados do artigo.

2 Inicialmente, o termo "cadeia de valor global" foi utilizado por especialistas em uma reunião promovida pela Fundação Rockefeller, em 2004, que recebeu o nome de Global Value Chain Initiative (GVCI). CGV como um conceito holístico logo se tornou dominante e passou a ser uma preocupação principal de organizações multilaterais, países, empresas e instituições sociais sobre questões empresariais, econômicas, políticas e sociais relacionadas com a globalização da produção e das finanças. Contudo, foi desenvolvido na esteira das discussões sobre globalização nos anos 1990, como explica um dos principais formuladores da GVC Initiative (HUMPHREY, 2004, p. 1): "A variety of terminologies have been used to try and capture the development of new global production and distribution systems, including 'global production networks' (HENDERSON et al., 2002), 'international production networks' (UNCTAD, 2002b), 'globalization of production' (GOUREVITCH et al., 2000), 'global commodity chains' (GEREFFI and KORZENIEWICZ, 1994) and 'international value-added chain' (KOGUT, 1984). This paper uses the term 'global value chain' as it is derived analytically from the work of the global value chain initiative". 


\section{DESENVOLVIMENTISMO CLÁSSICO: A INDÚSTRIA COMO PROTAGONISTA}

Nessa seção, retomam-se alguns dos conceitos centrais que formaram a base teórica do desenvolvimentismo clássico, entendido como aquele que se baseava especialmente em três pilares: estratégia industrialista, políticas protecionistas e atuação direta do Estado como planejador e investidor ${ }^{3}$. Note-se, desde já, que a estratégia industrialista trazia implicitamente a ideia de que, quanto mais completa e complexa fosse a estrutura produtiva de determinada nação, maiores seriam as suas possibilidades em termos de aproveitamento do efeito multiplicador da renda e do emprego. A grande dificuldade residia em como promover tal estratégia em um contexto tão adverso quanto o do subdesenvolvimento. Em boa medida, a profundidade dos problemas, em sua maior parte de caráter estrutural, justificava a adoção de políticas protecionistas e da atuação direta do Estado.

Relacionada com as especificidades dos problemas socioeconômicos enfrentados pelas nações subdesenvolvidas, a chamada Economia do Desenvolvimento ganhou forma e expressão no pós II Guerra Mundial, no contexto da Guerra Fria. Por isso, em boa medida, a literatura que dela procede possui um caráter mais reformista - destaque-se, especialmente, a influência do pensamento de Keynes - do que propriamente revolucionário. Contribuíram para a sua composição e o seu desenvolvimento uma série de pensadores, conhecidos como pioneiros do desenvolvimento. No geral, além de se debruçarem sobre as particularidades das nações mais atrasadas, também buscaram derivar estratégias de desenvolvimento.

Vejamos, a seguir, definições e conclusões derivadas de alguns desses pensadores - Rosenstein-Rodan, Nurkse, Hirschman, Kalecki, Prebisch e Furtado - em termos da estratégia de desenvolvimento que julgavam adequadas para que os países mais atrasados superassem a sua condição de subdesenvolvimento. Em boa medida, a obra dos pioneiros selecionados contemplam os elementos que caracterizam a base do pensamento desenvolvimentista ${ }^{4}$. Dentre outras tantas questões, os pioneiros elencados auxiliam na compreensão de por que: a obediência à teoria das vantagens comparativas ricardiana não seria uma escolha adequada para os países subdesenvolvidos uma vez que reforçavam sua condição inicial de periferia; a industrialização não ocorreria de maneira espontânea; o subdesenvolvimento e a pobreza a ele subjacente possuem uma

3 Para um bom resumo sobre a evolução das ideias dos velhos e novos desenvolvimentismos, ver Carneiro (2012).

4 Outros autores pioneiros também contribuíram, significativamente, para a formação do pensamento desenvolvimentista. Por delimitação de escopo e espaço, optou-se por não abordá-los diretamente. Para mais detalhes sobre os pioneiros, vide Cardoso (2012). 
tendência retroalimentadora. Dito de outro modo, de porque o subdesenvolvimento compunha uma armadilha histórica (FURTADO, 1992) e, por isso, demandava uma estratégia específica para a sua superação.

Para superar o subdesenvolvimento, Rosenstein-Rodan (1943) principalmente destacava a necessidade de promover a industrialização. A industrialização, por estar relacionada com maiores níveis de produtividade, seria essencial para a dissolução de uma característica das nações subdesenvolvidas: a existência de desemprego disfarçado - ou seja, pessoas alocadas em atividades produtivas de baixíssima produtividade - e seu impacto baixista sobre o nível de renda. Para industrializar, fazia-se necessário o enfrentamento de uma grande dificuldade inicial: a causação circular entre renda e industrialização, querendo dizer que a industrialização tendia a se desenvolver justamente onde já havia maior disponibilidade de renda. Ou seja, existiria uma tendência à concentração industrial, tanto dentro de uma nação - gerando, desigualdades regionais e, possivelmente, reforçando a condição inicial de heterogeneidade estrutural como entre nações - perpetuando, portanto, o hiato entre nações desenvolvidas e subdesenvolvidas.

Para reverter essa tendência, Rosenstein-Rodan indicava a necessidade de planejamento de uma industrialização em larga escala, fazendo-se necessária a atuação do Estado como coordenador dos projetos de investimento - não excluindo a captação de financiamento externo. Por meio do planejamento estatal da industrialização em larga escala, poder-se-ia garantir o balanceamento do processo de mudança, entre os diversos setores, levando à transformação em bloco. Os pontos cruciais do planejamento, por sua vez, diriam respeito ao treinamento planejado de mão de obra e à promoção do investimento em bloco, que permitiriam um melhor aproveitamento das economias externas pecuniárias e tecnológicas ${ }^{5}$. Assim, os efeitos de encadeamento positivos pela cadeia produtiva poderiam ser intensificados, permitindo a formação de um grande impulso, necessário para dar início ao processo de desenvolvimento. Com o amadurecimento da industrialização, as nações antes subdesenvolvidas poderiam participar da divisão internacional do trabalho de maneira mais virtuosa (CARDOSO, 2012).

Em uma linha semelhante de argumentação, Nurkse (1953) sugere que a estratégia de crescimento equilibrado haveria ser pensada em termos globais. Para o autor, as nações atrasadas deveriam diversificar sua pauta exportadora, bem como direcionar esforços para o desenvolvimento do mercado interno. A estratégia de industrialização

\footnotetext{
Economias externas tecnológicas relacionam-se com a formação de trabalho especializado, e as economias externas pecuniárias implicam que investimentos complementares horizontalmente resultariam em uma taxa de retorno maior para cada um dos investimentos tomados isoladamente.
} 
seria fundamental para superar o que Nurkse define como círculo vicioso da pobreza, análogo à causação circular entre renda e industrialização de Rosenstein-Rodan, sendo que no primeiro as relações circulares são aquelas que dificultam a formação de capital nos países atrasados, relacionadas tanto com o lado da oferta, quanto com o lado da demanda de capital. Havia pouco capital disponível, pois o nível de renda era muito baixo. E não havia incentivo para investir, porque o mercado interno era muito diminuto. Assim, o ponto comum das relações circulares relativas à demanda e à oferta de capital era a condição inicial dessas nações atrasadas: o baixo nível da renda, reflexo de baixos salários e produtividade.

Para o autor, o processo de transformação produtiva deveria ser planejado. O Estado, além de atuar de maneira direta na captação e no direcionamento de recursos, deveria disponibilizar garantias institucionais e políticas de incentivo que permitissem a sociedade atuar para superar o círculo vicioso da pobreza (CARDOSO, 2012). Ademais, o Estado deveria estar atento ao efeito adverso de incremento de demanda por bens de luxo, em decorrência do efeito demonstração - qual seja, de emulação dos padrões de consumo de países de renda mais elevada. A consequência poderia ser uma pressão por importação desses bens e/ou da concentração de investimentos nas indústrias produtoras de tais bens. No primeiro caso, estaria aberta uma brecha para desvio do efeito multiplicador da renda e do emprego para fora do país; no segundo caso, implicaria um crescimento industrial não equilibrado e, por isso, com menor potencial de transformação.

De Hirschman (1958) vale destacar especialmente os efeitos de retroalimentação permitidos pelos investimentos - os encadeamentos para frente e para trás - em setores industriais. $\mathrm{O}$ autor deriva das próprias mudanças - e desequilíbrios - desencadeadas pelo processo, uma fonte crucial de efeitos positivos ao desenvolvimento. Segundo Cardoso (2012), na abordagem de Hirschman é como se boa parte das soluções dos círculos viciosos que geram o subdesenvolvimento fosse propriedade emergente do próprio processo, não podendo, por conseguinte, ser pressuposta a priori.

Ainda, para Hirschman, o investimento constitui a variável-chave para superar as dificuldades enfrentadas pelas nações subdesenvolvidas por conta de seu efeito de complementaridade, segundo o qual, no evolver da dinâmica produtiva, um determinado setor tomaria as vantagens das economias externas geradas por uma expansão prévia, ao mesmo tempo em que criaria novas economias externas a serem exploradas por outros setores. Para o autor, seria justamente a falta de interdependência e de encadeamentos entre os setores que compõem o sistema econômico nacional uma das características típicas das nações subdesenvolvidas. Mesmo porque, essas nações permaneciam baseadas principalmente na agricultura, especialmente a de subsistência, caracterizada por raros (ou fracos) efeitos de encadeamento. Por isso, a necessidade de 
recorrer à estratégia industrialista: naquele contexto, a industrialização equivalia a estruturas produtivas mais complexas, com maior potencial de gerar encadeamentos para frente e para trás e, portanto, de aumentar o efeito multiplicador.

A contribuição de Kalecki (1968) destaca a idiossincrasia do desemprego e do subemprego nos países subdesenvolvidos, onde eles resultariam mais da limitação de capacidade produtiva do que da insuficiência de demanda efetiva. O autor aponta especialmente para o gargalo na oferta de bens de primeira necessidade (alimentos), que dependem da elasticidade (ou inelasticidade) da produção agrícola. O resultado de qualquer crescimento no emprego implicaria, caso a produção agrícola não respondesse prontamente ao incremento de demanda, uma resposta inflacionária dos preços dos alimentos. Desse modo, para evitar a pressão inflacionária e não agravar a questão do desemprego e do subemprego, fazia-se necessária a expansão da produção agrícola além da consecução da estratégia industrialista. Caso contrário, a condição inicial de heterogeneidade estrutural seria recrudescida. Assim, para Kalecki, o problema crucial das nações subdesenvolvidas é aumentar o investimento, não com o intuito de incrementar somente a demanda efetiva, mas de expandir principalmente a capacidade produtiva.

Para Kalecki, haveria, no entanto, ao menos três obstáculos ao incremento do investimento: o próprio volume de investimento privado, que poderia não alcançar uma taxa desejável; poderia não haver recursos disponíveis para produzir mais bens de capital; e mesmo que as primeiras duas questões estivessem resolvidas, a fim de evitar uma potencial pressão inflacionária, restaria o problema de garantir uma oferta adequada de bens de primeira necessidade, especialmente em decorrência do aumento do nível de emprego. Principalmente, quanto a assegurar uma produção adequada de bens de primeira necessidade, sem que observassem mudanças institucionais substanciais, relacionadas especialmente com a posse de terra, não seria possível acelerar o desenvolvimento agrícola. Por isso, à semelhança dos estruturalistas latino-americanos, Kalecki (1968) aponta para a necessidade de promoção de reforma agrária para racionalizar a produção agrícola. Para o enfrentamento dos diversos obstáculos, fazia-se necessário planejar não somente o volume, mas também a estrutura do investimento buscando um relativo balanceamento entre os setores produtivos. Para tal, o autor indica que deveria haver intervenção governamental, seja via investimento, seja via planejamento.

Prebisch (1949) dirige sua crítica diretamente à teoria do comércio internacional pautada pela teoria das vantagens comparativas, segundo a qual os frutos do progresso técnico tenderiam a ser distribuídos equitativamente entre as nações participantes do comércio internacional. Seguindo esse raciocínio, as nações especializadas na produção de bens primários, além de não precisarem, não deveriam se industrializar. O pioneiro desenvolveu seu raciocínio baseado na definição teórica da relação centro-periferia: centro, pois é o epicentro dos ciclos relacionados com o progresso tecnológico 
especialmente; e periferia porque absorve os efeitos dele. A estratégia de desenvolvimento recomendada por Prebisch - e pelos demais cepalino-estruturalistas - aponta a necessidade de transformar a estrutura produtiva tornando-a mais moderna via industrialização, permitindo extrair as vantagens das interações internacionais e possibilitando escaparda tendência à deterioração dos termos de troca, que se moveriam adversamente à periferia primário-exportadora. Dado o progresso técnico oriundo do centro, a tendência à deterioração dos termos de troca dos bens primários seria inevitável e irreversível, por conta da diferença entre as elasticidades renda das importações de bens primários e de bens manufaturados - sendo a primeira baixa e a segunda alta. Assim, a manutenção da tradicional divisão internacional do trabalho - nações primário-exportadoras e nações industrializadas - implicaria a manutenção e o fortalecimento do hiato de renda entre os dois grupos de nações.

Os motivos principais para a insuficiência dinâmica do sistema econômico periférico fariam referência, segundo Prebisch, ao desequilíbrio entre a produtividade e os investimentos realizados, que apresentaria como consequência dinâmica a incapacidade de absorver o fator mão de obra - justamente a sua dotação mais abundante -, tanto a que se deslocava de atividades menos capitalizadas quanto a que acabava sendo economizada pela própria capitalização. Boa parte da explicação desse desequilíbrio estaria na própria natureza da tecnologia que as nações periféricas estavam assimilando, porquanto não estava adaptada às suas dotações de recursos.

Segundo Prebisch, "[a] prova da robustez dinâmica de um sistema está em sua capacidade de imprimir velocidade ao ritmo de desenvolvimento e de melhorar progressivamente a distribuição de renda" (1963, p. 455). Para tal, seriam imprescindíveis as transformações estruturais, como: contenção do consumo dos grupos de mais alta renda - direcionada aos bens de luxo - e a necessidade de alterar o regime de posse da terra, altamente concentrada. Para o autor, o incremento de produtividade no setor primário poderia implicar uma melhor retenção do fruto do seu progresso técnico, tanto no que se refere à esfera internacional, incrementando a pauta exportadora, quanto à interna, satisfazendo o mercado interno de forma mais eficiente. Como consequência, a disparidade de renda entre o campo e a cidade poderia ser atenuada, funcionando como um meio de redistribuir melhor a renda.

Tanto no que se refere ao planejamento de investimentos quanto à política redistributiva, infere-se de Prebisch que o Estado desempenha papel crucial como elaborador e executor do plano de desenvolvimento. Entretanto, para que fossem alcançados resultados satisfatórios relativos a melhoras no padrão de vida do conjunto da população, far-se-ia necessário que, além da transformação da estrutura produtiva, ocorresse uma profunda transformação social. De outro modo, os benefícios da transformação produtiva seriam concentrados apenas pelas elites, perpetuando e até acentuando as desigualdades existentes. 
Em sua vasta contribuição para a literatura sobre desenvolvimento econômico, Celso Furtado também chama a atenção sobre como, ao longo da história, em cada paradigma tecnológico-industrial advindo do centro, a inserção externa de Estados periféricos se deu de forma avessa ao desenvolvimento. Furtado (1974) destaca como barreiras, nesse sentido, a concentração da riqueza e da renda, em que o comércio se organiza em função dos interesses das elites nas economias que lideravam a revolução industrial; o aumento da taxa de exploração nos países periféricos e a apropriação do excedente adicional pelos grupos dirigentes locais (da qual resultou a ruptura cultural manifestada no processo de modernização); a orientação do processo de industrialização em função dos interesses da minoria modernizada (que resulta em uma taxa de salário real presa ao nível de subsistência); o custo crescente da tecnologia requerida para acompanhar, mediante produção local, os padrões de consumo dos países centrais (o que facilita a penetração das grandes empresas de ação internacional); a necessidade de fazer face aos custos crescentes em moeda estrangeira da produção destinada ao mercado interno, abrindo o caminho para um perfil exportador menos sofisticado (essencialmente primário, no contexto em que escreve o autor) e a desequilíbrios macroeconômicos associados à taxa de câmbio e à restrição externa.

Assim, a ponte para a inserção externa transformar a matriz produtiva por meio da mudança estrutural seriam mecanismos institucionais para evitar aquelas velhas marcas sugeridas por Furtado, com as ressalvas devidas à visão estagnacionista ${ }^{6}$, e também com a preocupação de se promover igualdade. Em primeiro lugar, far-se-ia necessária uma verdadeira modernização agrícola. Essa viria por meio de profunda e extensa reforma agrária e desconcentração fundiária, um processo complexo que transforma as estruturas sociais no campo relacionadas com contextos geográficos, demográficos e culturais. Assim, seriam dadas condições para que a agricultura de subsistência elevasse sua pro-

6 Vale ressaltar que, principalmente com relação ao progresso tecnológico no centro, a visão de Furtado foi considerada estagnacionista: ao aprofundar a substituição de importações e internalizar na periferia técnicasdo centro intensivas em capital e poupadoras de mão de obra (diminuindo a relação entre produto e capital marginal), limitariam os efeitos multiplicadores sobre o mercado interno - o que seria exagerado ainda pela oferta ilimitada de força de trabalho, que previne a transferência dos ganhos de produtividade aos salários. Entretanto, conforme desenvolvido na crítica de Tavares e Serra (1970), a relação produto e capital poderia não cair porque a motivação dos investimentos em tecnologia depende da expectativa sobre a demanda efetiva (eficiência marginal do capital), portanto a adoção daquelas tecnologias não seria inequívoca. Além disso, "os efeitos da intensidade do progresso técnico ou do aumento da produtividade do trabalho cujo aumento poderia assegurar a lucratividade dos investimentos. Isso significa que a relação produto/capital só cairia, arrastando a lucratividade e o crescimento, se o aumento da produtividade fosse menor do que o incremento da dotação de capital por trabalhador" (CARNEIRO, 2012, p. 755). 
dutividade e rentabilidade, melhorando também a oferta de alimentos interna e a participação de pequenas e médias propriedades nas exportações.

Analogamente, deveriam haver condições para que o arranjo político e institucional se tornasse mais democrático e prevenisse exageros no comportamento rentista, ampliando o poder de barganha dos trabalhadores e reduzindo o dos grandes capitais, empresários e financistas,para que os lucros auferidos (nos setores exportadores em particular, mas também no restante da economia) ${ }^{7}$, fossem reinvestidos na diversificação e sofisticação das atividades econômicas, também com maior participação de empreendimentos de menor porte. Mais além, idealmente, também para que os ganhos de produtividade fossem repassados aos salários - com aumento da sua parcela no excedente - melhorando o padrão de "desarollo hacia dentro".

Assim, feita uma breve síntese de alguns dos pensadores que estruturam o pensamento desenvolvimentista, a partir dos quais se derivou a necessidade estratégica de promover a industrialização na periferia, podem-se destacar algumas conclusões. Guardadas suas diferenças e até possíveis incompatibilidades - teóricas e/ou metodológicas -, os elementos e as discussões levantadas pelos pioneiros, embora com entonações ou destaques variados, apontam para a necessidade de: transformação da estrutura produtiva, a fim de impactar a pauta exportadora e importadora; promoção de reformas estruturais - relacionadas com diversos aspectos, especialmente aqueles com impacto distributivo; e de planejamento estatal, por meio da elaboraçãode planos nacionais de desenvolvimento.

As intervenções e direcionamentos, por meio do Estado, sugeridos pelos pioneiros, seriam necessários no contexto do subdesenvolvimento, porque os círculos viciosos da pobreza de Nurkse implicariam a tendência de perpetuação das disparidades, dos desequilíbrios internos e outros diversos problemas refletidos principalmente na perpetuação de heterogeneidade estrutural - questão enfatizada por Kalecki e outros autores estruturalistas - e na sujeição aos efeitos de deterioração dos termos de troca da dinâmica centro-periferia. Para fazer frente a essas causações circulares cumulativas (MYRDAL, 1957) do círculo da pobreza seria preciso um grande impulso, tal como definira Rosenstein-Rodan, para o qual concorreriam a promoção de investi-

\footnotetext{
7 "Em uma estrutura subdesenvolvida em que os lucros auferidos no setor exportador não se inserem no fluxo interno de renda, a referida pressão [para elevação dos salários] não se manifestará. Neste caso particular, o excedente de mão-de-obra pode ser absorvido sem que o quadro de distribuição de renda venha sofrer modificação significativa. Depreende-se daí que uma economia subdesenvolvida não deve ser considerada isoladamente do sistema de divisão internacional do trabalho em que está inserida, e que, em suas raízes, o subdesenvolvimento é um fenômeno de dominação, ou seja, de natureza cultural e política” (FURTADO, 1983, p.148).
} 
mentos em bloco, abrangendo os diversos setores da economia, permitindo o aproveitamento das economias externas e dos encadeamentos para frente e para trás que Hirschman ressaltou. Ou seja, sem a promoção da industrialização - e a sua consequência esperada (embora não garantida) de complexificação da estrutura produtiva, implicando melhor aproveitamento do efeito multiplicador da renda e do emprego - a periferia estaria fadada à armadilha histórica do subdesenvolvimento - associada à baixa e desigual distribuição da renda e da riqueza.

A industrialização substitutiva de importações, diretriz das políticas econômicas no período desenvolvimentista, foi uma estratégia de desenvolvimento especialmentelevada a cabo pelo Brasil e por outros países latino-americanos como uma alternativa à manutenção dos papéis da clássica divisão internacional do trabalho em consonância coma teoria das vantagens comparativas. Os pioneiros do desenvolvimento - alguns deles brevemente abordados por essa seção - compuseram a fundamentação teórica para a consecução desse modelo de desenvolvimento, que imprimia à industrialização o caminho promissor para a periferia se aproximar economicamente do centro.

\section{A NOVA DIVISÃO CENTRO E PERIFERIA NO CONTEXTO DAS CADEIAS GLOBAIS DE VALOR}

O que é centro e o que é periferia no século XXI? A julgar pelo critério renda per capita, o cenário da distribuição interestatal não é muito diferente da época dos pioneiros, tampouco do final dos anos 1970, quando do início da mundialização financeira e produtiva liderada pelas grandes empresas transnacionais dos países desenvolvidos e do sistema financeiro internacional baseado no dólar flexível (SERRANO, 2002).

Tomando-se o Produto Interno Bruto (PIB) per capita em paridade do poder de compra (PPP), de acordo com dados do Fundo Monetário Internacional (FMI), ainda se nota uma clara divisão "norte/sul". Conforme se depreende na Figura 1, a despeito da elevação geral do PIB de 1980 para 2016, as economias mais ricas permanecem praticamente as mesmas (PIB superior a U\$ 25.000 PPP em 2016, e superior a U\$ 5.000 PPP em 1980): Europa Ocidental e do Norte, EUA, Canadá, Austrália, Nova Zelândia, Japão e Arábia Saudita. A periferia do sistema compreende os demais países, ampla maioria do mundo - dentre os quais apenas os Tigres Asiáticos (Taiwan, Hong Kong, Singapura e Coreia do Sul) alavancaram sustentadamente seu padrão de vida, enquanto somente a Líbia caiu do grupo dos mais ricos. 


\section{Figura 1 - Mapas do Produto Interno Bruto per capita, em Paridade do Poder de Compra, médias 1980 e 2016}

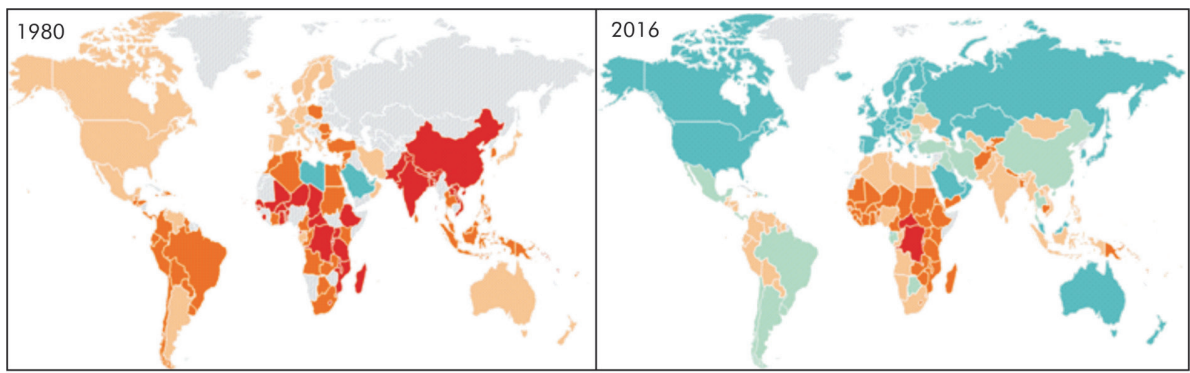

25.000 ou mais $\quad 15.000-25.000 \square 5.000-15.000 \square 1.000-5.000 \square$ Abaixo de $1.000 \square$ Dados Indisponiveis

Fonte: FMI, World Economic Outlook, 2018.

Contudo, o desenvolvimento econômico é um processo complexo, cujo sucesso não se resume ao PIB per capita. O debate estimulado pelos pioneiros sobre este conceito se estendeu nas décadas seguintes, reconhecendo - já a partir de meados da década de 1960, de acordo com Arndt (1987) - que os objetivos do desenvolvimento precisariam incorporar dimensões distributivas, nosâmbitos econômico, político e social. Em boa medida, os pensadores de viés estruturalista - Prebisch, Furtado e Kalecki, por exemplo - haviam se dado conta da não suficiência da estratégia industrialista para resolver os problemas profundamente arraigados no contexto do subdesenvolvimento. Problemas esses que tenderiam, inclusive, a implicar um esgotamento precoce da própria estratégia industrialista. Isso ocorreria porque, como explicado anteriormente, sem uma combinação com as chamadas reformas de base - agrária, tributária, política -, a industrialização na periferia tenderia a acentuar dois de seus principais problemas: a heterogeneidade estrutural e a concentração de renda e riqueza.

A intuição dos pioneiros revelou-se certeira: além da permanência de uma alta desigualdade de renda interestatal, solidificou-se também um acentuado desequilíbrio quanto à distribuição de renda interna dos países e à superação da pobreza. Desse modo, em 2011, conforme os dados do Banco Mundial (2015), quase a totalidade da extrema pobreza mundial (medida pela renda diária inferior a U\$ 1,25 ao dia) localizava-se nos países que não pertencem ao grupo dos que detêm maior PIB per capita. Especialmente, na África Subsaariana, o contingente populacional extremante pobre chegava a representar mais de $50 \%$ da população. Quando se considera o índice de distribuição sugerido por Palma (2011), conhecido como razão de "Palma" (Palma ratio), comparando-se a razão entre as porções da renda total de uma nação apropria- 
das pelos $10 \%$ mais ricos e $40 \%$ mais pobres da população ${ }^{8}$, os países mais equânimes se resumem aos da Europa Central e do Norte, Japão e Líbia - nem mesmo os EUA estão na lista.

A despeito da permanência de uma brutal desigualdade de renda entre os países - desde o pós-guerra e, particularmente, após os anos 1980 -, os padrões de comércio, produção e finanças sofreram profundas transformações, acompanhando as novas tendências gerenciais e administrativas das empresas e da internacionalização do capital - por um lado-, e das relações geopolíticas - de outro. No frigir desses determinantes, o fato é que a progressiva fragmentação das cadeias produtivas das empresas transnacionais dos países avançados envolveu a transferência de uma série de atividades e tarefas, não somente estágios produtivos, para países em desenvolvimento. Portanto, as CGV agrupam produtores, processadores, compradores, vendedores e consumidores - separados pelo tempo e espaço - que desempenham toda a gama de atividades realizadas para gerar um produto ou serviço, como pesquisa \& desenvolvimento, design, produção, marketing, distribuição e suporte ao consumidor final (GEREFFI e STARK, 2016).

Os diferentes engajamentos nas CGV desde os anos 1980, assentados no novo paradigma tecnológico, baseados nas tecnologias de informação e telecomunicações (PEREZ, 2002), estiveram associados a processos de globalização industrial e financeira que reformularam a especialização produtiva da periferia e do centro. Menos da metade dos países com maior parcela de manufaturas em relação ao total de bens exportados em 2016, vistos na Figura 2, estavam no mapa em 1980 - quando as razões tradicionais da divisão centro/periferia começavam a mudar. No entanto, no grupo de 2016, há muitos países que detêm alta exportação de manufaturas com níveis de renda baixos ou médios. Mesmo considerando-se a participação de manufaturas de alta tecnologia nas exportações de manufaturados, ainda persistem contrastes expressivos no nível de renda em cada faixa, segundo dados do Banco Mundial. 8 A razão assume esses quintis porque, conforme descoberta do autor, a porção intermediária mantém parce-
la relativamente estável sobre a renda total em quase todos os países ao longo do tempo (PALMA, 2011). 


\section{Figura 2 - Participação das manufaturas nas exportações totais de bens $(1980 / 2016)$ e participação das manufaturas de alta tecnologia nas exportações totais de manufaturas (1988/2016)}

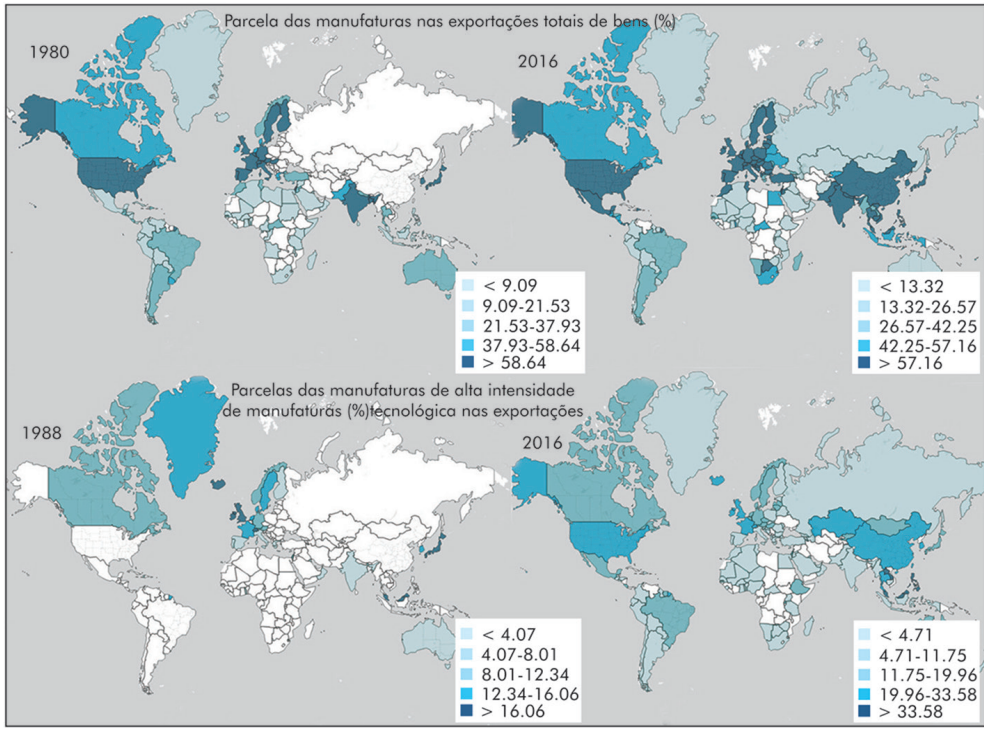

Fonte: Banco Mundial.

Assim, comparando-se o PIB per capita e a parcela das manufaturas nas exportações, identificam-se países ricos atuando tanto no mercado de manufaturas quanto de bens primários, sendo, ainda, que o mercado de serviços tem se tornado cada vez mais importante nas atividades de alto valor nas cadeias produtivas dos outros dois setores, de forma que o comércio internacional em termos de porte e relevância é também (TIVA/OCDE). Analogamente, têm-se países em desenvolvimento exportadores de manufaturas, mas ainda longe de ascenderem ao nível de renda dos desenvolvidos.

Uma das variáveis indicativas da inserção nas CGV é a reexportação de bens intermediários importados, já que aponta para as relações de trocas do núcleo da cadeia produtiva. No mundo, a parcela reexportada de bens intermediários importados sobre o total importado de bens intermediários avançou de 32\% em 1995 para 39\% em 2011, seguindo a exploração dos dados TIVA apresentados na Figura 3. Dentre os países da Organização para a Cooperação e Desenvolvimento Econômico (OCDE), em 2011 esse indicador foi maior naqueles que são parte do núcleo das “fábricas" das cadeias da União Europeia, Luxemburgo (90\%), Hungria (71\%), Irlanda (79\%), Eslováquia (67\%), República Tcheca (63\%) e Islândia (62\%). Destaca-se também o alto indicador mexicano, de $57 \%$, por ser a fábrica da integração regional da Área de Livre Comércio da América do Norte (North American Free Trade Agreement - NAFTA). Comparando-se com 1995, a 
parcela das reexportações dos importados de bens intermediários cresceu significativamente na OCDE na Polônia, Coreia do Sul, Alemanha, Hungria, Islândia e República Tcheca. Por outro lado, este indicador em grandes economias, como EUA, Japão, Austrália e Reino Unido é próximo ou inferior à média mundial. No caso dos países fora da OCDE, a parcela reexportada de bens intermediários importados sobre o total importado de bens intermediários é elevada na Singapura (73\%), Malásia (65\%), Taipei (64\%), Bulgária (57\%), em Camboja (55\%) e Hong Kong (55\%). Em contraste, alguns países apresentam uma parcela bem abaixo da média mundial em 2011, como Colômbia (15\%), Brasil (18\%), Indonésia (20\%), Arábia Saudita (20\%), Índia (27\%) e Argentina (28\%).

Outra forma de medir a integração às cadeias, conhecida como indicador para trás das CGV, é o percentual de valor adicionado importado nas exportações brutas de bens e serviços de um país - também ilustrado na Figura 3. Tomando-se primeiramente a OCDE em 2011, o indicador para trás das CGV repetiu o mesmo conjunto de países europeus entre os que apontaram maior resultado de reexportação de intermediários: Luxemburgo (59\%), Hungria (49\%), Eslováquia (47\%), República Tcheca (46\%), Irlanda (43\%), Eslovênia (36\%) e Estônia (35\%). Neste caso, a Coreia do Sul (42\%) apresentou indicador mais elevado relativamente aos outros países, diferentemente do que nas reexportações de bens intermediários importados, invertendo posições com o México (32\%). Também neste indicador, os menores valores em 2011 foram de Austrália (14\%), Japão (15\%) e EUA (15\%).

Analogamente, em 2011, no topo e no final do ranking dos países não pertencentes à OCDE quanto ao indicador de valor adicionado importado nas exportações brutas, constavam os mesmos grupos de exportadores do que no indicador de reexportação de bens intermediários importados. Com maior índice para trás nas CGV estão Taipei (44\%), Singapura (42\%), Malásia (41\%), Bulgária (40\%), Tailândia (39\%), Malta (37\%), Camboja (37\%) e Vietnã (36\%). Dentre os países com indicadores menores, Arábia Saudita (3\%), Brunei (4\%), Colômbia (8\%), Brasil (11\%), Indonésia (12\%), Rússia (14\%) e Argentina (14\%).

Entre os países da amostra de fora da OCDE (de 1995 a 2011), o conteúdo importado nas exportações quase triplicou em Camboja, na Índia e Argentina. No Brasil, o aumento foi de $38 \%$ (passando de 7,83\%em 1995, chegando a $12,74 \%$ em 2008, com queda abrupta para 9,99\% em 2009, para depois se elevar até 10,77\% em 2011). Já os países da OCDE que assinalaram maior crescimento do valor adicionado importado em suas exportações entre 1995 e 2011 foram Coreia do Sul, Hungria, Luxemburgo, Turquia e Polônia. No caso dos países fora da OCDE, foram Camboja, Vietnã, Índia, Tailândia e Taipei.

Esses dois indicadores estão positivamente correlacionados, porém não guardamcorrelação com o tamanho das exportações totais das economias, nem com o nível de 
renda per capita (REIS e ALMEIDA, 2016). Assim como há grandes exportadores,como EUA e Rússia, que apresentam baixos indicadores para trás nas CGV e de reexportação de bens intermediários importados - e o Brasil, em menor grau; existem também grandes exportadores que têm um engajamento mediano nas CGV - como Alemanha, Reino Unido, Itália, Espanha, Suíça e Coreia. E ainda, dentre os países mais engajados nas $\mathrm{CGV}$, tomando-se por base esses indicadores, há grandes e pequenos exportadores - como China em contraposição à Luxemburgo, Malta e Singapura -, que apresentam discrepantes graus de desenvolvimento econômico? ${ }^{9}$

Assim, como tendência geral, percebe-se uma maior integração dos diversos países às CGV dos anos 1990 para 2010, no sentido de que na maioria, o percentual importado do valor das exportações aumentou. Entretanto, esse indicador não leva à regra alguma sobre as vantagens de estar mais ou menos engajado às cadeias. Isso porque os diferentes portes das economias, suas diversas especializações, os padrões de comércio e esquemas de interação regional conferem caráter autêntico a cada caso. E também porque tal indicador ainda não fornece a informação relevante sobre o tipo de atividade que o país realiza na cadeia de valor, para então se derivarem conclusões sobre as suas vantagense desvantagens para o desenvolvimento.

9 Analisando mais a fundo a indústria de transformação, Reis e Almeida (2016) verificam uma heterogênea participação do valor adicionado estrangeiro nas exportações dos diferentes tipos de bens manufaturados em 2011, de acordo com dados TIVA. Em geral, os países da OCDE apresentam indicadores para trás mais elevados do que os países de fora da OCDE, especialmente nas exportações de coque, petróleo refinado e energia nuclear (em média, valor acima de 60\%) na maioria dos países da Europa central e do Leste. Isso porque importam petróleo cru e reexportam refinado. No outro oposto, a Noruega, grande produtora das duas categorias de petróleo, possui este indicador bem baixo (15\%). Esta tendência de alto indicador por causa da necessidade de importação da matéria-prima básica se repete para produtos minerais não metálicos e equipamentos de transporte, em menor grau. 
Figura 3 - Reexportação de bens intermediários importados em relação ao total importado de bens intermediários (em \%, à esquerda) e valor adicionado importado nas exportações brutas em relação ao total exportado de bens e serviços (em \%, à direita) em 1995 e 2011
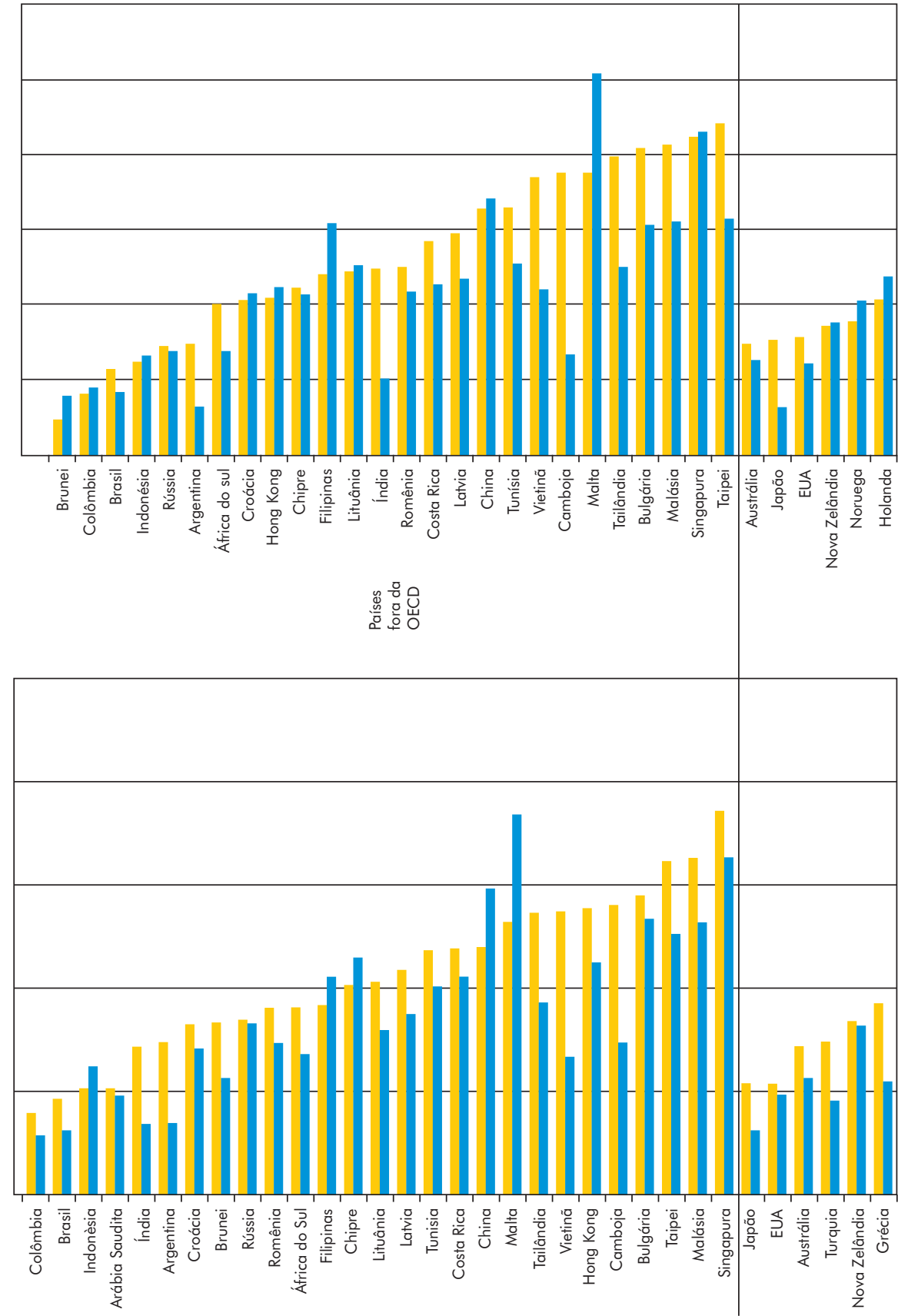


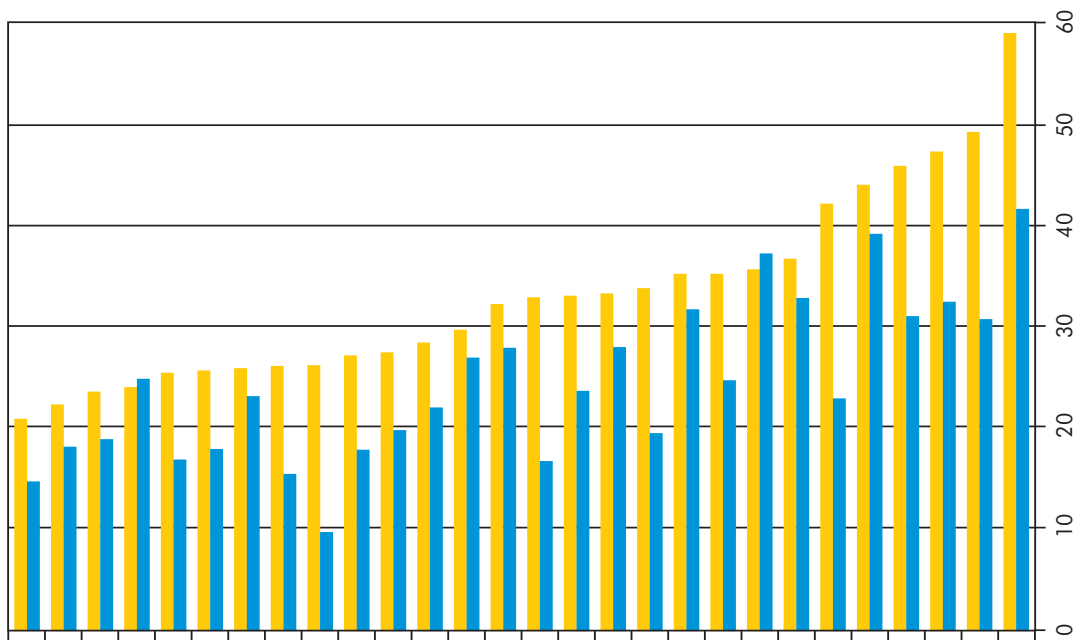

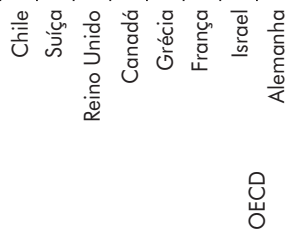

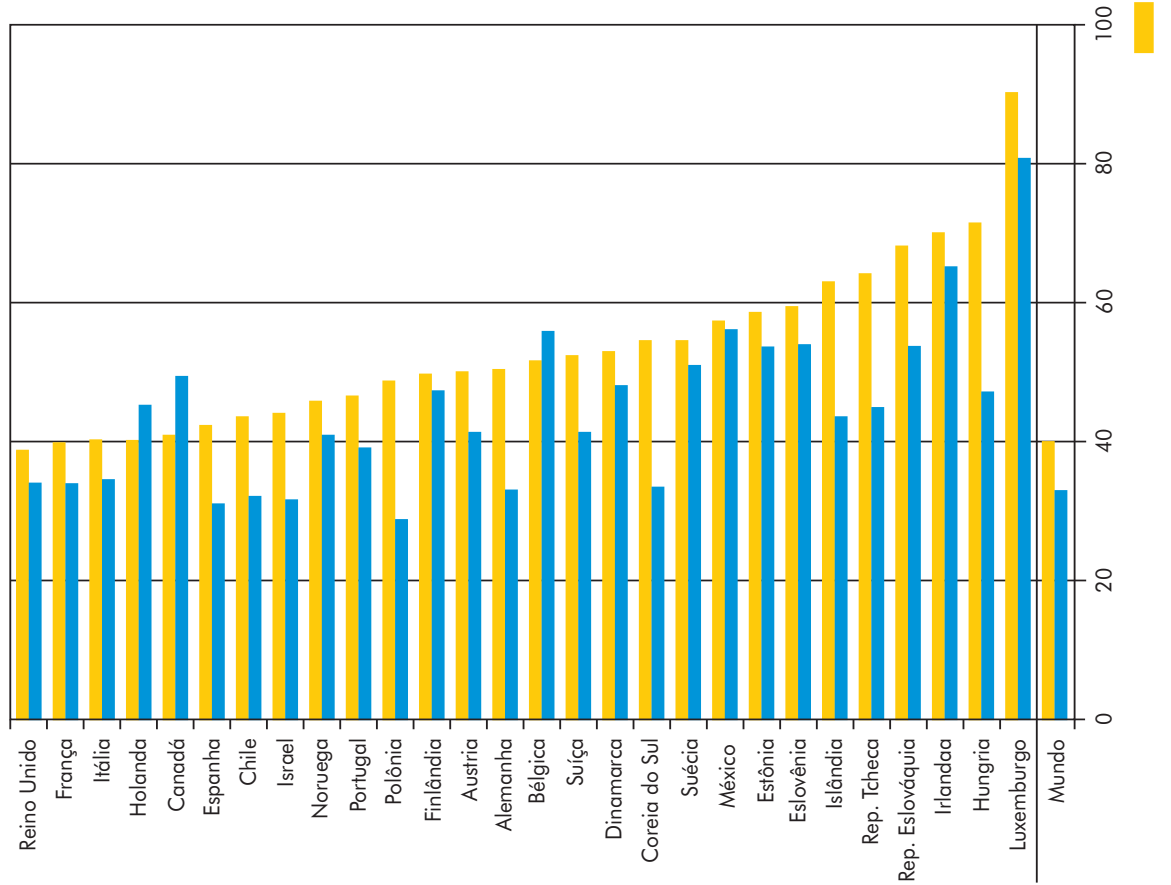

Fonte: Elaboração própria com base em dados de TIVA (OCDE/OMC). 
Neste sentido, Rodrik (2006) lembra a importância do que se exporta para entender o desenvolvimento econômico de um país. E nesse espírito de analisar a relação entre o perfil exportador e a trajetória de desenvolvimento, que Hidalgo e Hausmann (2009) sugerem o indicador decomplexidade tecnológica. Oindicador combina os critérios de diversificação (quantidade de produtos exportados por um país) e ubiquidade (quantidade de países que exporta cada produto). A complexidade econômica é maior quanto menos ubíquos e mais diversificados os produtos exportados. Destarte, examinando a complexidade, Hartmann et al. (2015, p. 11) encontram uma "forte e robusta correlação" entre a estrutura produtiva dos países e a desigualdade de renda: quanto mais complexa, menor a desigualdade. Entre os produtos mais complexos (lista superior a 1.000 itens), a maior parte é da indústria de transformação de alta intensidade tecnológica - o que reforça o argumento da importância da industrialização para o desenvolvimento econômico.

Figura 4 - Ranking da complexidade econômica, 2011

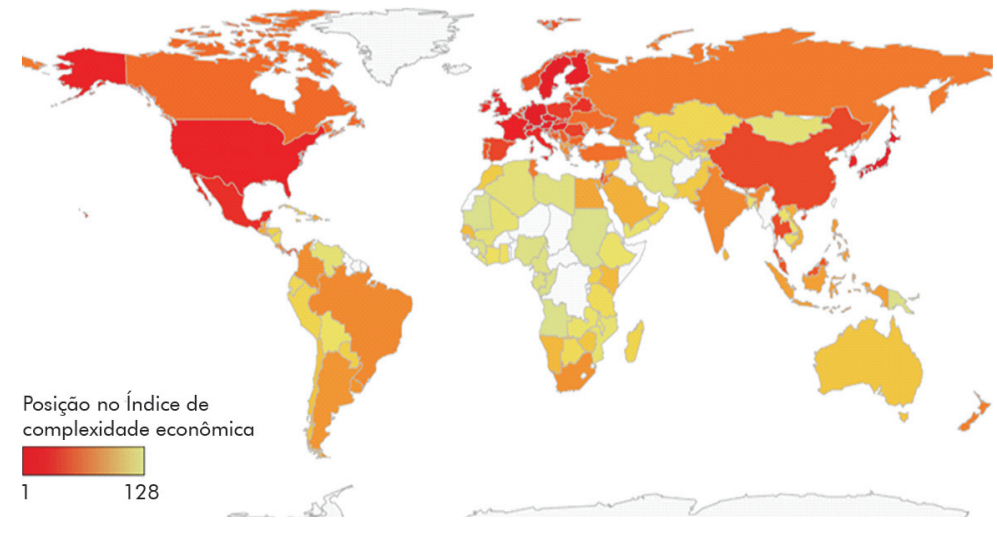

Fonte: Atlas da Complexidade.

Os 30 países mais complexos são, em sua maioria, mas não exclusivamente, de alta renda, como ilustra o mapa da Figura 4. Há também países ricos que não estão no topo da lista - principalmente por conta da questão da ubiquidade: Noruega, Emirados Árabes e Austrália. Entretanto, os 70 países menos complexos do ranking de mais de uma centena de países são de baixa renda. Mais além, há que se lembrar que muitos dos maiores exportadores de alimentos são países desenvolvidos, graças à alta produtividade do setor de alimentos (KALECKI, 1968). Esse progresso consiste em um mecanismo-chave para se superar a heterogeneidade estrutural. Seu desenrolar, vale ressaltar, em geral, é liderado por razões políticas, como reformas institucionais, como no regime macroeconômico, na política industrial ou na legislação sobre a propriedade - também como colocaram Kalecki e os estruturalistas latino-americanos. 
Como fica patente na Figura 5, em 2016 os países que possuíam uma elevada produtividade média do trabalho na agricultura, em geral, eram de alta renda (exceto Argentina, por exemplo), de forma que esse indicador também continua atual para simbolizar a separação centro/periferia. Mais do que aumentar a produtividade, o que distinguiu os países que superaramo subdesenvolvimento foi a modernização agrícola (SENGHAAS, 1985). Esta última é um processo complexo que transforma as estruturas sociais no campo relacionadas com contextos geográficos, institucionais e demográficos específicos - integrando a economia e propiciando a redução das desigualdades intersetoriais.

\section{Figura 5 - Valor adicionado por trabalhador na agricultura, florestal e pesca, 2016 (em U\$ 2010 mil)}

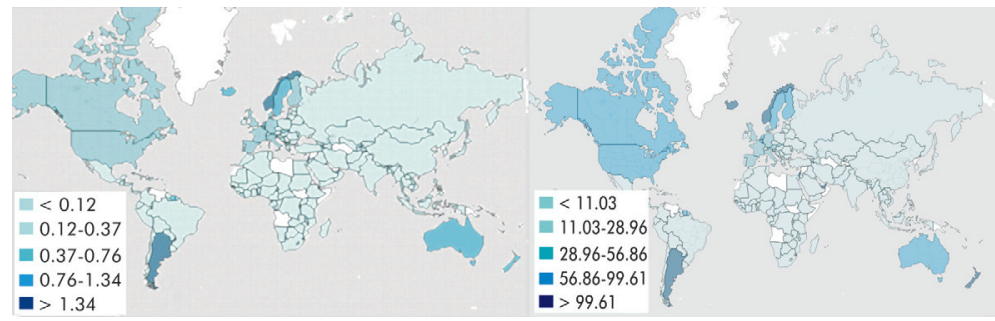

Fonte: Banco Mundial.

Dessa forma, o incremento da produtividade agrícola é uma condição necessária ao desenvolvimento econômico, mas não suficiente - já que não basta que o seja no setor exportador, mas, também, no que serve à economia interna. Da mesma forma, a complexidade comercial, na direção de produtos industriais de maior intensidade tecnológica, parece ser uma condição necessária, mas não suficiente para o desenvolvimento. Conforme interpretou Gala (2015), "não é difícil perceber que o desenvolvimento econômico pode ser tratado como o domínio de técnicas de produção mais sofisticadas que em geral levam à produção de maior valor adicionado por trabalhador". Consequentemente, ainda segundo o autor, o tecido produtivo mais sofisticado das indústrias tem relação direta com o maior conhecimento e a qualificação dos trabalhadores, com níveis mais elevados de salários e de condições de trabalho. Todavia, o indicador de complexidade tecnológica tampouco é preciso para se avaliar as consequências da especialização comercial para o desenvolvimento, pois se refere a bens finais, e não às atividades das cadeias, além de nada dizer sobre a origem doméstica ou não do valor adicionado dos bens exportados. Do mesmo modo, não contabiliza os serviços - que representam mais de um quarto do comércio mundial em 2016 (OMC) e mais da metade do valor dos bens industriais (MANYIKA, 2012). 
Depreende-se desta constatação a sugestão de que a teoria do desenvolvimento dos pioneiros pode ser retomada de uma forma mais simples para a interpretação da divisão de trabalho entre centro e periferia a partir da especialização comercial nas CGV: se antes contrapunha a especialização em atividades primárias às manufatureiras, hoje separa participação nas atividades de alto valor adicionado ou não. Então, sofisticar a participação nessas cadeias, constitui-se em um caminho para o desenvolvimento econômico - o que a literatura tem discutido atualmente por meio da noção de upgrading. Simplificando, deve ser entendida como a melhoria econômica e social das atividades e tarefas desempenhadas por trabalhadores e trabalhadoras de empresas e países, passando de atividades de baixo valor para atividades de valor relativamente alto, que alavanquem tanto as condições materiais de trabalho quanto a quantidade e qualidade dos empregos criados no seu entorno (BARRIENTOS et al., 2011a; BARRIENTOS et al., 2011b).

Contudo, como ponderam Milberg e Winkler (2010), há de se pensar cuidadosamente sobre a associação entre upgrading econômico e social nas CGV, pois não tendem a ser endógenas ao funcionamento do mercado, tal qual suposto pelas teorias mainstream. Isso porque os efeitos de transbordamento de um setor nãosão automáticos, considerando principalmente que os ganhos de produtividade em uma cadeia podem estar sendo capturados pelas empresas líderes - ou seja, a associação entre desempenhar atividades mais sofisticadas com altos salários não é tão direta e, mesmo se for, não dinamiza necessariamente o tecido produtivo -, como os desenvolvimentistas já haviam apontado, conforme crítica de Furtado (1974) apresentada na Seção 1. Neste sentido, aproximando as conclusões de Milberg e Winkler às dos pioneiros do desenvolvimento, como o upgrade econômico e social pode não ser uma consequência natural do processo de modernização industrial, as políticas públicas devem ter a preocupação de estabelecer esta ponte concretamente.

Porém, remanesce um problema empírico para se entender a relação entre upgrading e desenvolvimento: ainda não existem bases de dados consolidados (apenas estudos de casos) que informam a especialização em atividades e tarefas dos países, até porque são em geral informações sigilosas - justamente o diferencial competitivo das estratégias empresariais, principalmente das grandes TNC, sobre a governança das $\mathrm{CGV}^{10}$. Outra dificuldade empírica reside na mensuração dos efeitos da especialização

10 Há cinco tipos de governança para Gereffi et al. (2005): mercados, modulares, cadeias de valor, relacionais, cativos e hierarquizados - em escala de menos a mais vertical, ou do menor ao maior grau de coordenação explícita ou de assimetria de poder. A operação da governança, de acordo com os autores, depende de três fatores: "a complexidade das transações entre firmas", "o grau em que essa complexidade 
comercial (e do upgrading) sobre o desenvolvimento econômico, que se dão pelos mecanismos que fazem a ponte entre as estruturascomercial e produtiva. Tais mecanismos dependem de fatores institucionais e estruturais enfatizados diferentemente pelas várias abordagens da literatura desenvolvimentista.

De modo geral, elencam-se como determinantes estruturais as dotações iniciais, os efeitos de encadeamento, o progresso técnico e o território. Do lado das instituições, o Estado e seus meios de atuação, em especial, o regime macroeconômico, política industrial, comercial e tecnológica, investimento público; e os interesses externos, os direitos de propriedade, a educação e o sistema nacional de inovação. Independentemente de qual fator prepondere, é preciso ter em mente que o que se produz importa também;e que a especialização comercial e a produtiva precisam ser compreendidas conjunta e dinamicamente no sistema centro-periferia.

Os pioneiros da Economia do Desenvolvimento sugeriram que para crescer os países pobres necessitavam de alguma fonte de expansão da demanda agregada, como gastos públicos ou endividamento, e até mesmo um novo fôlego advindo da demanda externa a partir da descoberta ou criação de novos mercados de exportação. E, sinteticamente, para aqueles autores, os limitantes do desenvolvimento a partir da especialização comercial dependiam: (a) da distribuição de renda e riqueza, notadamente no campo; (b) das características do mercado de commodities; (c) da intensidade dos efeitos de encadeamento do setor de exportação; (d) da aplicação das rendas de exportações primárias; (e) do regime macroeconômico e da restrição externa; e (f) dos conflitos e das associações de poder e riqueza no âmbito da competição interestatal, entre capitalistas e de luta de classes.

O primeiro limitante - acerca da desigual distribuição de renda e riqueza, notadamente no campo -, refere-se à apropriação dos meios de produção e da terra por uma minoria privilegiada, oligopolistas em seus mercados agrícolas, industriais ou de serviços. Os lucros extraordinários que o maior poder de mercado lhes confere retroalimenta sua força política, de forma que seus interesses permaneçam sendo priorizados nas políticas de Estado. Além disso, no caso da desigualdade rural, como Kalecki observara, a produção agroexportadora tem como contrapartida gargalos na oferta de bens de primeira necessidade (alimentos), que se tornam pressão inflacionária sobre os preços dos alimentos. Além disso, a especialização exportadora nos países em desenvolvimento, em geral, é marcada pela heterogeneidade estrutural, cuja superação não acontece pelo simples evolver dos mecanismos de mercado. Por isso, os pioneiros

pode ser mitigada por meio da codificação" e "a medida em que os fornecedores têm as capacidades necessárias para satisfazer as exigências dos compradores". 
defenderam reformas que promovessem redistribuição, bem como orientassem a estrutura do investimento doméstico buscando um relativo balanceamento entre os setores produtivos - mas cujos efeitos para o desenvolvimento dependeriam também da superação dos demais limitantes.

O segundo (b) deles trata da noção apresentada na Seção 1 de que a especialização poderia comprometer o desenvolvimento em médio e longo prazo, se as exportações tendessem a apresentar termos de troca decrescentes em relação às importações. A deterioração dos termos de troca, entretanto, é um conceito constantemente colocado à prova - dadas as oscilações de preços. Diferentes cortes temporais levam a tendências diversas. Quando tomada a série longa desde o final do século XIX, comprova-se uma deterioraçãoainda que tenha havido ciclos (como o dos anos 1990 e 2000) -, que ocasionou a reprimarização das pautas de diversos países em desenvolvimento (CEPAL, 2007).

A oferta ilimitada de mão de obra e a premissa de que a produção do país em desenvolvimento não afeta o preço mundial da commodity pouco sofisticada, traduzem-se em uma remuneração baixa, exogenamente determinada ao nível do salário de subsistência. O fluxo de renda desta economia depende do setor moderno (e da função de produção condicionada pelo avanço tecnológico), ou melhor, da taxa de investimento no mesmo e de sua demanda por trabalho. A partir dessas duas últimas variáveis, define-se o produto bruto a ser distribuído entre as classes em forma de salários, aluguéis e lucros. Por sua vez, a taxa de investimento do setor exportador depende, afinal, da taxa de lucro dos capitalistas e do crescimento da demanda mundial (FINDLAY e LUNDAHL, 2002). O mecanismo fundamental que elevaria os níveis de salário seria a produtividade, que depende do dinamismo do mercado de cada produto exportado, mas também de diversos mecanismos institucionais e estruturais, a começar pelo excedente entre oferta e demanda de trabalho. A produtividade tenderia a ser tanto maior quanto mais sofisticada e/ou complexa fosse a produção em que se especializa. Soma-se a isso a perspectiva de que, com a ampliação da absorção do fator trabalho, dinamizada pelos próprios efeitos de encadeamento que as atividades mais complexas provocam, derivar-se-ia uma tendência de valorização dos salários.

No que diz respeito à intensidade dos efeitos de encadeamento (c), a contribuição teórica de Hirschman encontra-se bem incorporada ao contexto atual por trabalhos matério-espacial em sociologia e geografia, herdeiros da staple theory, que enfatizam os aspectos microeconômicos da especialização sob uma perspectiva neomarxista do sistema capitalista internacional. As características espaciais e materiais são um dos parâmetros das tecnologias (e da produção em geral), dos mercados (e das instituições em geral) e da interação de forças (geo)políticas (BUNKER e CICANTELL, 2005).

A transformação de uma economia especializada pouco complexa para uma economia diversificada e não ubíqua, e quiçá sofisticada, está relacionada com a criação e 
difusão de inovações em certas indústrias, que implementam novos processos produtivos de maior produtividade, podendo incorrer, à la Hirschman, em efeitos de encadeamento e processos de aprendizado que dinamizam o restante da estrutura produtiva. Para que a diversificação também signifique sofisticação, os desafios maiores são quanto aos efeitos de encadeamento entre os ofertantes (upstream) e os compradores (downstream). No caso da mudança estrutural, se as indústrias upstream são dominadas por multinacionais ou protegidas, seu poder provoca transferências de renda dos produtores de bens acabados para os intermediários. Já no caso da sofisticação, são necessárias complementariedades e que o upstream provenha insumos de maior qualidade e menor custo, que confiram maior competitividade aos produtores de bens finais (DONER, 2009).

Já o limitante (d) leva em consideração que as rendas da exportação constituem fonte crucial de divisas para reduzir a restrição externa na balança de pagamentos de países em desenvolvimento, conforme Prebisch. A especialização produtiva e a comercial atraem e geram divisas, trazendo receitas adicionais para o governo e lucro para os capitalistas que dominam esse setor exportador. Caso as receitas advindas da taxação sejam revertidas em gasto público (corrente e de investimento, este último em infraestrutura e/ou atividades empresariais), e/ou os lucros sejam reinvestidos em indústrias de maior valor adicionado, o setor exportador seria mais capaz de acelerar a mudança estrutural na economia e potencialmente sustentar o processo de crescimento de longo prazo. Afinal, a industrialização na visão desenvolvimentista é tomada como o principal meio para obter uma parcela dos benefícios do progresso tecnológico e para aumentar progressivamente o padrão de vida da população nacional (OCAMPO e PARRA, 2006).

O regime macroeconômico e, principalmente a restrição externa (e), podem ser limitantes para o desenvolvimento como alertaram os desenvolvimentistas e seus críticos, como Tavares $(1972,1985)$. A transformação estrutural virtuosa depende da coerência do respectivo regime macroeconômico, tanto melhor quanto mais as políticas fiscais e monetárias se adequarem aos objetivos sociais do desenvolvimento (BIANCARELLI et al., 2013), zelando por uma taxa de câmbio real competitiva, controle de capitais, financiamento de investimentos de longo prazo, seguridade energética e alimentar, transferência e autonomia tecnológica etc. Como bem resume CEPAL (2014), a macroeconomia para o desenvolvimento deve ter um enfoque integrado, que priorize a mudança produtiva e nivele por cima as capacidades e oportunidades sociais, considerando o ciclo e a tendência de crescimento de longo prazo (real e nominal). Portanto, o Estado continua a ter papel fundamental, pois lhe cabe liderar o encaminhamento político das reformas estruturais de ordem fiscal, tributária, cambial, administrativa, previdenciária e agrária - relacionadas, especialmente,com aquelas de 
impacto distributivo - para redistribuir progressivamente os ganhos de produtividade; e de planejamento estatal, por meio da elaboração de planos nacionais de desenvolvimento, que almejem a melhoria das condições do investimento privado e também da rede de bens públicos (MEDEIROS, 2015) ${ }^{11}$.

Finalmente, lembrando o limitante (f), a possibilidade de transformação do modelo exportador dos países periféricos é escassa no jogo de competição capitalista internacional (FIORI, 2004), haja vista o pequeno número de países desenvolvidos no mundo e a manutenção da divisão centro e periferia, ainda que repaginada no que se refere à sua especialização produtiva, no século XXI. A nova divisão internacional do trabalho preserva, ainda,uma velha fórmula: estabelecer fontes diretas de matérias-primas e semi-fabricados que possibilitam economias de escala, ganhos de produtividade e aumento de excedentes no centro.

Assim, como conclusão, entende-se que a divisão centro/periferia a partir da distinção entre aqueles que geram progresso técnico (centro) e os que simplesmente recebem seus efeitos (periferia) - bem como das suas consequências sobre a tendência de comportamento resultante dos termos de troca e seus impactos sobre a dinâmica econômica nacional -, permanece, porém remodelada. Permanece, porque o grupo de países centrais e periféricospraticamente não mudou desde meados do século XX. Ainda há uma expressiva diferença de renda entre países ricos e os demais, que coincide, mesmo que não exatamente, com as diferenças no padrão complexidade das exportações ecom os diferenciais de produtividade na agricultura, e, por conseguinte, com a apreensão mais virtuosa ou não das benesses do progresso tecnológico. Porém, no contexto atual das CGV, não vale mais a mera divisão manufaturas/produtos primários.

Quanto à estratégia mais indicada para tentar gerar desenvolvimento e superar a armadilha do desenvolvimento, esta também não necessariamente coincide com a ideia de industrialização como pré-requisito para o desenvolvimento e para a transformação da pauta importadora e exportadora, tal como preconizado pelos pioneiros. Por outro lado, permanece o princípio de que atividades mais complexas - e, portanto, com mais tecnologia e conhecimento associados - possuem maior potencial de geração de efeitos de encadeamento e, por isso, quem se especializa nelas possui maiores

11 "Uma macroeconomia para o desenvolvimento não pode dissociar o ciclo e a estabilidade (real e nominal) da mudança estrutural nem de um aumento da taxa de crescimento de longo prazo. Essa articulação deve ocorrer em um enfoque integrado, que priorize, de maneira explícita, a mudança produtiva e nivele por cima as capacidades e oportunidades sociais. Por sua vez e conforme destacado, as políticas sociais devem acompanhar esse processo, sobretudo nas fases transitórias da mudança estrutural em que ainda não se tenha conseguido universalizar a via produtiva como principal caminho para a inclusão com bem-estar" (CEPAL, 2014, p. 16). 
chances de gerar crescimento e desenvolvimento - desde que se observem as mudanças estruturais associadas especialmente à distribuição de renda e riqueza. Essas atividades mais complexas não necessariamente se restringem ao setor industrial - ou ainda, a atividades industriais específicas - e podem estar associadas aos setores agrícola e de serviços. Aliás, conforme abordado acima, a superação da heterogeneidade estrutural continua sendo um dos grandes desafios dos países em desenvolvimento, especialmente no que diz respeito à produtividade agrícola.

\section{CONCLUSÕES}

Este artigo propôs a reconciliação entre a realidade da organização atual do comércio internacional, baseado nas cadeias globais de valor às lições dos pioneiros da Economia do Desenvolvimento. A reconfiguração do debate sobre desenvolvimento dos países periféricos por meio de tal reconciliação mostra-se importante na medida em que: passado mais de meio século desde a estruturação do pensamento desenvolvimentista, a divisão entre nações ricas e nações pobres continuou praticamente a mesma; a configuração do comércio internacional mudou, e com ela mudaram também os tradicionais papéis sintetizados pelo conceito prebischiano de centro-periferia; e a divisão internacional do trabalhointernacional se tornou ainda mais chave para compreender o desempenho das nações.

No que se refere ao novo contexto, fundamentalmente, a discussão teórica dos pioneiros do Desenvolvimento sobre os mecanismos que tornam a inserção externa virtuosa ainda possuem elementos apropriados para interpretar as possibilidades de desenvolvimento econômico por meio da inserção nas CGV. Nesse sentido, buscou-se argumentar que a forma de inserção externa é crucial para o potencial de desempenho socioeconômico. Respondendo à questão se continuaria válida a clássica configuração centro-periferia, conclui-se que na atual dinâmica centro-periferia os papéis do centro e da periferia se tornaram mais difusos, mas sua separação é mais reflexo do grau de complexidade e sofisticação de suas estruturas produtiva e comercial do que propriamente do setor (primário/indústria/serviços), em que se pese que a produtividade agrícola continua sendo o diferencial mais gritante entre os países dos dois grupos.

Após mais de meio século desde que as ideias abordadas desenvolvimentistas foram gestadas, a industrialização no sentido do upgrading para as atividades de maior valor adicionado pode ser um caminho promissor para o desenvolvimento com igualdade, se acompanhada de mudanças institucionais e estruturais favoráveis e facilitadoras. Por um lado, devem trazer efeitos de transbordamento para as demais atividades econômicas domésticas, dirimindo a heterogeneidade estrutural e alavancando crescimento e redistribuição de renda. Ao contrário, o engajamento apenas por meio de 
atividades que adicionam pouco valor contribuem pouco ou nada para o desenvolvimento econômico, considerando seus impactos negativos em termos de dependência tecnológica, vulnerabilidade externa, consequências ambientais e sociais (condições de trabalho, seguridade, poluição, devastação, esgotamento de recursos etc.).

O que vai determinar o sucesso do padrão de inserção externa, tal como alertavam os pioneiros do desenvolvimento, será a ampliação da capacidade tecnológica doméstica e de sua contribuição para elevar a produtividade e os salários do setor exportador e das demais atividades da economia. Tal associação depende, afinal, de um conjunto de mecanismos que vão desde a distribuição das dotações iniciais de fatores e da terra, passando pelas estruturas dos mercados, à atuação do Estado e de outras instituições internas e externas que condicionam a trajetória econômica e política doméstica.

Assim, a inquietude original dos pioneiros sobre como se inserir nesse sistema desigual continua atual. Mais além, são também atuais os mecanismos gerais identificados por aqueles autores para compreender as possibilidades de desenvolvimento da periferia por meio da inserção externa em um contexto mais complexo das cadeias globais de valor, zelando pela superação dos limitantes apresentados na Seção 2 do artigo: (a) da distribuição de renda e riqueza, notadamente no campo; (b) das características do mercado de commodities; (c) da intensidade dos efeitos de encadeamento do setor de exportação; (d) da aplicação das rendas de exportações primárias; (e) do regime macroeconômico e da restrição externa; e (f) dos conflitos e associações de poder e riqueza no âmbito da competição interestatal, entre capitalistas e de luta de classes. Afinal, o desenvolvimento socioeconômico envolve mudanças institucionais e estruturais quantitativas qualitativas, no sentido de elevar a renda e o padrão de vida da sociedade, eliminando ao mesmo tempo as desigualdades.

\section{REFERÊNCIAS}

ARNDT, H.W. Economic Development - the History of an Idea. Chicago/London: The University of Chicago Press, 1987.

ATLAS OF ECONOMIC COMPLEXITY. HARVARD, MIT. Disponível em: <http://atlas.cid. harvard.edu/>. Acesso em: 24 ago. 2018.

BANCO MUNDIAL. World Development Indicators. Banco Mundial, várias datas. Disponível em: $<$ http://data.worldbank.org/products/data-visualization-tools>. Acesso em: 24 ago. 2018.

BARRIENTOS, S.; GEREFFI, G.; ROSSI, A. Economic and social upgrading in global production networks: a new paradigm for a changing world. International Labour Review, v. 150, n. 3-4, p. 319-40, 2011a.

BARRIENTOS, S. et al. Decent work in global production networks: framing the policy debate. International Labour Review, v. 150, n. 4, p. 299-317, 2011 b. 
BUNKER, S.; CICANTELL, P. "Matter, space, time, and technology: how local process drives global systems”. In: CICANTELL, P. S.; SMITH, D. A.; SEIDMAN, G. Nature, raw materials, and political economy. Londres: Elsevier, 2005.

CARDOSO, F. G. A armadilha do subdesenvolvimento: uma discussão do período desenvolvimentista brasileiro sob a ótica da Abordagem da Complexidade. Tese (Doutorado em Economia do Desenvolvimento) - Faculdade de Economia e Administração, Universidade de São Paulo, São Paulo, 2012.

CARNEIRO, R. M. Velhos e novos desenvolvimentismos. Economia e Sociedade, nº especial, p. 749-778, 2012.

CEPAL - COMISSÃO ECONÔMICA PARA A AMÉRICA LATINA E O CARIBE. Progreso técnico y cambio structural em America Latina. Documento de proyecto. Comissão Econômica para a América Latina, Nações Unidas, 2007.

CEPAL - COMISSÃO ECONÔMICA PARA A AMÉRICA LATINA E O CARIBE. Mudança estrutural para a igualdade: uma visão integrada do desenvolvimento. Santiago do Chile: Nações Unidas, abr. 2014.

DONER, R. The politics of uneven development: Thailand's economic growth in comparative perspective. Cambridge: Cambridge University Press, 2009.

DUNNING, J. The eclectic (OLI) paradigm of international production: past, present and future. Int. J. Economics of Business, v. 8,n. 2, p. 173-190, 2001.

FINDLAY, R.; LUNDHAL, M. Resource-led growth - a long-term perspective: the relevance of the 1870-1914 experience for today's developing economies. Working Papers, UNU WIDER, n. 162, 2002.

FIORI, J. L. "De volta à questão da riqueza de algumas nações”. In: FIORI, J. L. (Org.). Estados e moedas no desenvolvimento das nações. Petrópolis: Editora Vozes, 1999.

FIORI, J. L. “Formação, expansão e limites do poder global”. In: FIORI, J. L. (Org.). O poder Americano. Editora Vozes: Petrópolis, 2004.

FURTADO, C. O mito do desenvolvimento econômico. Rio de Janeiro: Paz e Terra, 1974.

FURTADO, C. Teoria e política do desenvolvimento econômico. São Paulo: Abril Cultural, 1983.

FURTADO, C. "Economia do Desenvolvimento". Curso ministrado na PUC-SP em 1975. In: FURTADO, C. Arquivos Celso Furtado 2. Rio de Janeiro: Editora Contraponto; Centro Internacional Celso Furtado de Políticas para o Desenvolvimento, 2008[1975].

FURTADO, C. Brasil - a construção interrompida. São Paulo: Paz e Terra, 1992.

FMI - FUNDO MONETÁRIO INTERCIONAL. World Economic Outlook. Data Mapper. FMI, várias datas. Disponível em: <http://www.imf.org/> Acesso em: 24 ago. 2018.

GALA, P. A vingança dos estruturalistas. Blog PAULO GALA Economia, finanças e investimentos, 05 fev. 2015. Disponível em: <http://www.paulogala.com.br/?p=1803>. Acesso em: 24 ago. 2018.

GEREFFI, G.; FERNANDEZ-STARK, K. Global value chain analysis: a primer. 2. ed. Durham, NC: Center on Globalization, Governance \& Competitiveness, Duke University, 2016. 
GEREFFI, G.; HUMPHREY, J.; STURGEON, T. The governance of global value chains.Review of international political economy, n.12.1, p.78-104, 2005.

HARTMANN, D. et al. Linking economic complexity, institutions and income inequality. Papers, arXiv.org, 2015. Disponível em:<http://EconPapers.repec.org/RePEc:arx:papers:1505.07907>. Acesso em: 24 ago. 2018.

HAUSMANN, R. et al. The Atlas of Economic Complexity - Mapping Paths to Prosperity. Boston, MA: Center for International Development at Harvard University, Harvard Kennedy School, Macro Connections MediaLab, MIT, 2015.

HIDALGO, C. A.; HAUSMANN, R. The Building Blocks of Economic Complexity. Proc. Nat. Acad. Sci., v. 106, n. 26, p. 10570-10575, 2009.

HIRSCHMAN, A. O. The strategy of economic development. New Haven: Yale University Press, 1958.

HUMPHREY, J. Upgrading in global value chains. Working Paper, ILO Policy Integration Department, n. 28, 2004.

KALECKI, M. "A diferença entre os problemas econômicos cruciais das economias capitalistas desenvolvidas e subdesenvolvidas". In: MIGLIOLI, J. (Org).; FERNANDES, F. (Coord). Kalecki. Coleção Grandes Cientistas Sociais. São Paulo: Editora Ática, 1980[1968].

LIST, F. The national system of political economy. Philadelphia: J. B. Lippincott, 1856.

MANYIKA, J. et al. Manufacturing the future: The next era of global growth and innovation. McKinsey Global Institute, 2012.

MILBERG, W.; WINKLER, D. Economic and social upgrading in global production networks: Problems of theory and measurement. International Labour Review, n. 150, v. 3-4, p. 341$365,2011$.

MYRDAL, G. Teoria econômica e regiões subdesenvolvidas. 2. ed. Rio de Janeiro: Editora Saga, [1957] 1968.

NURKSE, R. Problemas da formação de capital em países subdesenvolvidos. Rio de Janeiro: Editora Civilização Brasileira, [1953] 1957.

OCAMPO, J. A.; PARRA, M.A. The dual divergence: growth successes and collapses in the developing world since 1980. DESA Working Paper, n. 24, jun. 2006.

OCDE - ORGANIZAÇÃO PARA A COOPERAÇÃO E DESENVOLVIMENTO ECONÔMICO; OMC - ORGANIZAÇÃO MUNDIAL DO COMÉRCIO. Interconnected economies: benefiting from global value chains. Preliminary Version. Genebra: OCDE, OMC, 2013.

OCDE - ORGANIZAÇÃO PARA A COOPERAÇÃO E DESENVOLVIMENTO ECONÔMICO; OMC - ORGANIZAÇÃO MUNDIAL DO COMÉRCIO. Trade in Value Added (TIVA). OCDE, várias datas. Disponível em: $<$ http://stats.OCDE.org/Index.aspx? DataSetCode=TIVA_ OCDE_WTO>. Acesso em: 24 ago. 2018.

PALMA, J. G. Homogeneous middles vs. heterogeneous tails, and the end of the 'Inverted-U': the share of the rich is what it's all about. Cambridge Working Papers in Economics, n. 1111, 2011.

PEREZ, C. Technological revolutions and financial capital. Chalteham, UK: Edward Elgar, 2002. 
PREBISCH, R. "Por uma dinâmica do desenvolvimento latino-americano". In: BIELSCHOWSKY, R. (Org.). Cinquenta anos de pensamento da CEPAL. Rio de Janeiro: Record, v. 1, 2000[1963].

PREBISCH, R. "O desenvolvimento econômico latino-americano e alguns de seus principais problemas". In: BIELSCHOWSKY, R. (Org.). Cinquenta anos de pensamento da CEPAL. Rio de Janeiro: Record, v. 1, 2000[1949].

REIS, C. F. B.; ALMEIDA, J. S. G. "Padrões de inserção exportadora nas cadeias globais de valor”. In: ENCONTRO DA ASSOCIAÇÃO KEYNESIANA BRASILEIRA, 9., 2016, São Paulo, FGV, 2016.

RODRIK, D. Industrial development: stylized facts and policies. Boston: John F. Kennedy School of Government, Harvard University, 2006. Disponível em: <ksghome.harvard.edu/ drodrik/ industrial\%20development.pdf>. Acesso em: 24 ago. 2018.

ROSENSTEIN-RODAN, P. "Problemas de Industrialização da Europa Oriental e Sul-Oriental" In: AGARWALA, A. N.; SINGH, S. P. (Eds.). A economia do subdesenvolvimento. Rio de Janeiro: Cia Editora Forense, 1969[1943].

SENGHAAS, D. The European experience - A historical critique of development theory. New Hampshire: Berg Publishers, 1985.

SERRANO, F. Do ouro imóvel ao dólar flexível. Economia e Sociedade, v. 19, n. 17, 2002.

TAVARES, M. C. T. Da substituição de importações ao capitalismo financeiro: ensaios sobre economia brasileira. Zahar Editores, 1972.

TAVARES, M. C. T. Acumulação de capital e industrialização no Brasil. Campinas: Editora da Unicamp, 1985.

UNCTAD - UNITED NATIONS CONFERENCE ON TRADE AND DEVELOPMENT. World Investment Report. Genebra, UNCTAD, 2013.

\section{ERRATA}

Na página 1:

Onde se lia:

“CENTRO E PERIFERIANAS CADEIAS GLOBAIS DE VALOR: UMA INTERPRETAÇÃO A PARTIR DOS PIONEIROS DO DESENVOLVIMENTO”

Leia-se:

"CENTRO E PERIFERIA NAS CADEIAS GLOBAIS DE VALOR: UMA INTERPRETAÇÃO A PARTIR DOS PIONEIROS DO DESENVOLVIMENTO”

Onde se lia:

"Professora Adjunta do Departamento de Ciências Econômicas da Universidade Federal do ABC (CECS/UFABC)” 
Leia-se:

"Professora Adjunta do Bacharelado em Ciências Econômicas da Universidade Federal do ABC (CECS/UFABC)”

Onde se lia:

"brofessora Adjunta do CECS/UFABC e pesquisadora visitante do programa IPODI Marie Curie na Technische Universität Berlin.”

Leia-se:

"brofessora Adjunta do Bacharelado em Ciências Econômicas da Universidade Federal do ABC (CECS/UFABC) e pesquisadora visitante do programa IPODI Marie Curie na Technische Universität Berlin."

Nas páginas 2 a 31, onde se lia:

"CARDOSO, F. G.; REIS, C. F. B. Centro e periferianas cadeias globais de valor: uma interpretação a partir dos pioneiros do desenvolvimento"

Leia-se:

"CARDOSO, F. G.; REIS, C. F. B. Centro e periferia nas cadeias globais de valor: uma interpretação a partir dos pioneiros do desenvolvimento"

Rev. Econ. Contemp. (2018) 22(3): e1822322 